\title{
Dynamic changes and diagnostic and prognostic significance of serum PCT, hs-CRP and s-100 protein in central nervous system infection
}

\author{
JIAAN WANG $^{1}$, XICAI WU $^{1}$, YUFENG TIAN $^{1}$, XUEYUAN LI $^{2}$, XIA ZHAO $^{3}$ and MIN ZHANG ${ }^{1}$ \\ ${ }^{1}$ Inspection Department, People's Hospital of Rizhao; ${ }^{2}$ Rizhao Disease Prevention and Control Center; \\ ${ }^{3}$ Nursing Department, People's Hospital of Rizhao, Rizhao, Shandong 276800, P.R. China
}

Received January 3, 2018; Accepted September 11, 2018

DOI: $10.3892 /$ etm.2018.6866

\begin{abstract}
The aim of the study was to analyze the dynamic changes and diagnostic and prognostic significance of serum procalcitonin (PCT), high-sensitivity C-reactive protein (hs-CRP) and s-100 protein in central nervous system infection. A total of 110 patients diagnosed with central nervous system infection in Department of Neurology in the People's Hospital of Rizhao from January 2014 to January 2016 were selected and retrospectively analyzed; they were divided into the bacterium $(n=70)$ and virus $(n=40)$ groups. Another 45 normal subjects were selected as the control group. PCT, hs-CRP and s-100 protein values in serum and cerebrospinal fluid were measured. The serum PCT, hs-CRP and s-100 protein levels in the bacterium group were significantly higher than those in the virus and control groups $(\mathrm{p}<0.05)$. The serum PCT, hs-CRP and s-100 protein levels in the bacterium and virus groups after treatment were obviously decreased compared with those before treatment $(\mathrm{p}<0.05)$. PCT, hs-CRP and s-100 protein levels in serum and cerebrospinal fluid in the bacterium and virus groups had no statistically significant differences after treatment $(\mathrm{p}>0.05)$. PCT, hs-CRP and s-100 protein levels in deaths in bacterium group were significantly higher than those in survivors $(\mathrm{p}<0.05)$. The serum PCT, hs-CRP and s-100 protein levels, can serve as important indexes for the diagnosis of central nervous system infection and their dynamic changes can be used to monitor the changes in disease condition, severity of bacterial infection and prognosis, providing help for the clinical treatment thereof.
\end{abstract}

\section{Introduction}

In clinical practice, especially in neurology department, central nervous system infection is a kind of common disease. The increasingly rapid aging of population has led to a gradual

Correspondence to: Dr Min Zhang, Inspection Department, People's Hospital of Rizhao, 126 Taian Road, Rizhao, Shandong 276800, P.R. China

E-mail: daowei26686444@163.com

Key words: central nervous system infection, PCT, hs-CRP, s-100, serum, cerebrospinal fluid increase in the number of patients with diabetes mellitus. The incidence rate of central nervous system infection has also been significantly increased (1). Central nervous system infection includes bacterial, viral, fungal and special infection, of which purulent meningitis and viral meningitis are more common. However, the characteristics of the disease, the abuse of modern antibiotics and the atypical disease symptoms, it is difficult to make a diagnosis and differential diagnosis.

The best diagnostic criteria of central nervous system infection are pathogenic and cerebrospinal fluid examinations, but it is hard for patients and their families to cooperate because of the longer detection time and the need for lumbar puncture, so the examinations cannot be widely applied clinically (2). At present, many studies have shown that in the acute phase of inflammatory response in human body, serum procalcitonin (PCT) and high-sensitivity C-reactive protein (hs-CRP) can be used as important indexes of inflammatory response. In healthy individuals, PCT and CRP levels are significantly lower than normal values; if infection occurs, especially bacterial infection, their concentrations in serum are significantly increased (3). S-100 protein mainly exists in neuroglial cells in various regions of central nervous system. It is generally believed that when the central nervous system is damaged, s-100 protein can be exuded from the neuroglial cell sap into the cerebrospinal fluid, and can continue to enter the blood from cerebrospinal fluid due to blood-brain barrier damage; the increase in serum s-100 level is a specific marker of central nervous system damage (4). Thus, the roles of serum PCT, hs-CRP and s-100 protein in evaluating the severity of disease and prognosis and guiding the treatment have gradually become research hotspots in recent years.

In the present study, we analysed the dynamic changes and diagnostic and prognostic significance of serum procalcitonin (PCT), high-sensitivity C-reactive protein (hs-CRP) and $\mathrm{s}-100$ protein in central nervous system infection and determined that PCT, hs-CRP and S-100 are useful as important indexes for the diagnosis of central nervous system infection.

\section{Materials and methods}

General data. A total of 110 patients diagnosed with central nervous system infection presenting at the Neurology Department in the People's Hospital of Rizhao (Rizhao, China) 
from January 2014 to January 2016 were selected and retrospectively analyzed. The patients were divided into the bacterium group ( $n=70)$, including 42 males and 28 females with an average age of $(35.68 \pm 3.69)$ years, and virus group $(n=40)$, including 21 males and 19 females with an average age of (34.71 \pm 3.12$)$ years. Another 45 normal subjects were selected as the control group, including 25 males and 20 females with an average age of $(36.23 \pm 2.16)$ years. All the subjects enrolled signed the written informed consent, and subjects in bacterium group and virus group agreed to receive lumbar puncture before and after treatment. There were no statistically significant differences in the general data in the bacterium, virus and control groups ( $p>0.05)$, and the data were comparable (Table I). All the subjects enrolled met the ethical requirements, and subjects in bacterium and virus groups were diagnosed with central nervous system infection via pathogenic and cerebrospinal fluid examinations without taking antibiotics before treatment. Exclusion criteria for the study were: patients with epidemic encephalitis B, tuberculosis or fungal encephalitis; patients complicated with immune diseases, other systemic infections or severe hepatic or renal impairment; patients who refused to receive lumbar puncture midway or with incomplete data. The study was approved by the Ethics Committee of the People's Hospital of Rizhao.

Methods. Vital signs of the cases enrolled were recorded after admission. Fasting serum $(2 \mathrm{ml})$ was drawn at 2 days after admission, and at 1,2 and 4 weeks after treatment in the early morning to detect the serum PCT, hs-CRP and s-100 protein levels. The bacterium and virus groups received the lumbar puncture at 2 days after admission and at 1 week after treatment, and $2 \mathrm{ml}$ cerebrospinal fluid was collected using a tube. PCT, hs-CRP and s-100 protein levels in cerebrospinal fluid in the two groups were detected, respectively. PCT value was detected using immunofluorescence chromatography, the kit was provided by BRAHMS (Thermo Fisher Scientific BRAHMS GmbH, Hennigsdorf, Germany), and a value $>0.5 \mathrm{ng} / \mathrm{ml}$ indicated positive. hs-CRP value was detected using immunoturbidimetry, the kit was provided by Guangzhou Wondfo Biotechnology Co., Ltd. (Guangzhou, China), and a value $>8 \mathrm{mg} / \mathrm{l}$ indicated positive. $\mathrm{s}-100$ protein was detected via enzyme-linked immunosorbent assay (ELISA) by testing physicians strictly according to the instructions of the kit provided by Shanghai Westang Biotechnology Co., Ltd. (Shanghai, China). With PCT $>0.5 \mathrm{ng} / \mathrm{ml}$, hs-CRP>8 mg/l and s-100>0.04 ng/dl as positive boundary values, sensitivity was calculated as true positive number/(true positive number + false negative number) $\mathrm{x} 100 \%$, specificity was calculated as true negative number/(true negative number + false positive number) x $100 \%$, respectively for PCT, hs-CRP and s-100 for the diagnosis of central nervous system infection. The combined detection serum PCT, hs-CRP and s-100 was diagnosed using sensitivity and specificity of central nervous system infection.

Statistical analysis. Statistical Product and Service Solutions (SPSS) 19.0 software (IBM,Armonk, NY,USA) was used for data processing. Data were collected and presented as (mean $\pm \mathrm{SD}$ ). The independent-samples t-test was used. Student's t-test or Tukey's post hoc test after one-way analysis of variance in SPSS were used to analyze the differences between the groups. $\mathrm{P}<0.05$ suggested that the difference was statistically significant.
Table I. Comparisons of general data among the three groups.

\begin{tabular}{lcccc}
\hline Groups & Case (n) & Male (n) & Female (n) & $\begin{array}{c}\text { Average age } \\
\text { (years) }\end{array}$ \\
\hline Bacterium & 70 & 42 & 28 & $35.68 \pm 3.69$ \\
Virus & 40 & 21 & 19 & $34.71 \pm 3.12$ \\
Control & 45 & 25 & 20 & $36.23 \pm 2.16$ \\
\hline
\end{tabular}

$P>0.05$, the difference is not statistically significant.

Table II. Comparisons of PCT, hs-CRP and s-100 protein levels among the three groups of patients before treatment.

\begin{tabular}{lcccc}
\hline Groups & $\begin{array}{c}\text { Case } \\
(\mathrm{n})\end{array}$ & $\begin{array}{c}\text { PCT } \\
(\mathrm{ng} / \mathrm{ml})\end{array}$ & $\begin{array}{c}\text { hs-CRP } \\
(\mathrm{mg} / \mathrm{l})\end{array}$ & $\begin{array}{c}\text { S-100 } \\
(\mathrm{ng} / \mathrm{dl})\end{array}$ \\
\hline Bacterium & 70 & $13.26 \pm 6.19$ & $51.31 \pm 8.26$ & $1.31 \pm 1.10$ \\
Virus & 40 & $0.61 \pm 0.18$ & $7.59 \pm 4.10$ & $0.83 \pm 0.21$ \\
Control & 45 & $0.48 \pm 0.11$ & $5.13 \pm 1.82$ & $0.53 \pm 0.11$ \\
p-value & & $<0.05$ & $<0.05$ & $<0.05$ \\
\hline
\end{tabular}

\section{Results}

Comparisons of PCT, $h s-C R P$ and $s-100$ protein levels among the three groups of patients before treatment. Serum was collected from patients before treatment (at 2 days after admission), and the serum PCT, hs-CRP and s-100 protein levels were detected. The serum PCT, hs-CRP and s-100 protein levels in bacterium group were significantly higher than those in the virus and control groups, and the differences were statistically significant $(\mathrm{p}<0.05)$. The serum PCT, hs-CRP and s-100 protein levels in virus group were higher than those in control group, but the differences were not significant (Table II).

Comparisons of PCT, $h s-C R P$ and s-100 protein levels in serum and cerebrospinal fluid between bacterium group and virus group before treatment. The bacterium and virus groups received lumbar puncture before treatment (at 2 days after admission). PCT, hs-CRP and s-100 protein levels in cerebrospinal fluid were detected and compared with the serum levels. There were no statistically significant differences in the PCT, hs-CRP and $\mathrm{s}-100$ protein levels between the two groups. $(\mathrm{p}>0.05)$ (Table III).

Comparisons of serum PCT, hs-CRP and s-100 protein levels between bacterium group and virus group before and after treatment. The serum was collected from patients after treatment (at 7 days after admission), and PCT, hs-CRP and s-100 protein levels were detected and compared with the serum levels before treatment. The results showed that the PCT, hs-CRP and s-100 protein levels in the bacterium and virus groups after treatment were significantly lower than those before treatment, and the differences were statistically significant $(\mathrm{p}<0.05)$; the differences in bacterium group were more significant (Table IV).

Comparisons of PCT, $h s-C R P$ and s-100 protein levels in serum and cerebrospinal fluid between bacterium group and virus 
Table III. Comparisons of PCT, hs-CRP and s-100 protein levels in serum and cerebrospinal fluid between bacterium and virus groups before treatment.

\begin{tabular}{|c|c|c|c|c|c|c|}
\hline \multirow[b]{2}{*}{ Groups } & \multicolumn{2}{|c|}{ PCT (ng/ml) } & \multicolumn{2}{|c|}{ hs-CRP (mg/l) } & \multicolumn{2}{|c|}{ S-100 (ng/dl) } \\
\hline & Serum & Cerebrospinal fluid & Serum & Cerebrospinal fluid & Serum & Cerebrospinal fluid \\
\hline Bacterium & $13.26 \pm 6.19$ & $14.01 \pm 5.76$ & $51.31 \pm 8.26$ & $55.29 \pm 9.01$ & $1.31 \pm 1.02$ & $1.41 \pm 1.05$ \\
\hline Virus & $0.61 \pm 0.18$ & $0.63 \pm 0.12$ & $7.59 \pm 4.10$ & $6.78 \pm 4.23$ & $0.83 \pm 0.02$ & $0.80 \pm 0.02$ \\
\hline
\end{tabular}

Table IV. Comparisons of serum PCT, hs-CRP and s-100 protein levels between bacterium and virus groups before and after treatment.

\begin{tabular}{|c|c|c|c|c|c|c|}
\hline \multirow[b]{2}{*}{ Groups } & \multicolumn{2}{|c|}{ PCT (ng/ml) } & \multicolumn{2}{|c|}{ hs-CRP (mg/l) } & \multicolumn{2}{|c|}{ S-100 (ng/dl) } \\
\hline & 2 days & 7 days & 2 days & 7 days & 2 days & 7 days \\
\hline Bacterium & $13.26 \pm 6.19$ & $0.59 \pm 0.18$ & $51.31 \pm 8.26$ & $5.96 \pm 2.39$ & $1.31 \pm 1.02$ & $0.05 \pm 0.02$ \\
\hline Virus & $0.61 \pm 0.18$ & $0.35 \pm 0.16$ & $7.59 \pm 4.10$ & $4.91 \pm 2.41$ & $0.83 \pm 0.02$ & $0.04 \pm 0.01$ \\
\hline P-value & \multicolumn{2}{|c|}{$<0.05$} & \multicolumn{2}{|c|}{$<0.05$} & \multicolumn{2}{|c|}{$<0.05$} \\
\hline
\end{tabular}

Table V. Comparisons of PCT, hs-CRP and s-100 protein levels in serum and cerebrospinal fluid between bacterium and virus groups after treatment.

\begin{tabular}{|c|c|c|c|c|c|c|}
\hline \multirow[b]{2}{*}{ Groups } & \multicolumn{2}{|c|}{ PCT (ng/ml) } & \multicolumn{2}{|c|}{ hs-CRP (mg/l) } & \multicolumn{2}{|c|}{ S-100 (ng/dl) } \\
\hline & Serum & Cerebrospinal fluid & Serum & Cerebrospinal fluid & Serum & Cerebrospinal fluid \\
\hline Bacterium & $0.59 \pm 0.18$ & $0.63 \pm 0.18$ & $5.96 \pm 2.39$ & $6.02 \pm 2.42$ & $0.05 \pm 0.02$ & $0.06 \pm 0.02$ \\
\hline Virus & $0.35 \pm 0.16$ & $0.44 \pm 0.20$ & $4.91 \pm 2.41$ & $5.93 \pm 2.38$ & $0.04 \pm 0.01$ & $0.04 \pm 0.02$ \\
\hline
\end{tabular}

group after treatment. The bacterium and virus groups received lumbar puncture after treatment (at 7 days after admission). PCT, hs-CRP and s-100 protein levels in cerebrospinal fluid were detected and compared with the serum levels. There were no statistically significant differences in the PCT, hs-CRP and s-100 protein levels between the two groups. $(\mathrm{p}>0.05)$ (Table V).

Comparisons of diagnostic values of single detection and combined detection of serum PCT, hs-CRP and s-100 protein levels. The sensitivity, specificity and accuracy of combined detection of serum PCT, hs-CRP and s-100 protein were 99, 90 and $95 \%$, respectively, which were superior to those of single detection of PCT, hs-CRP and s-100, or detection of PCT + hs-CRP, PCT + s-100 and hs-CRP + s-100. The differences in sensitivity and accuracy were statistically significant $(\mathrm{p}<0.05)$, but the difference in specificity was not statistically significant (Tables VI and VII).

Outcome and prognosis. In the bacterium group, 70 patients were enrolled, 4 of whom died due to severe intracranial infection ( $n=2)$ and systemic sepsis $(n=2)$; there was no discharge and transfer to another hospital. In the 4 deaths, the detection after admission showed that the serum PCT level was higher than $16.0 \mathrm{ng} / \mathrm{ml}$, CRP level was higher than $65 \mathrm{mg} / \mathrm{l}$ and s-100 protein level was higher than $15.0 \mathrm{ng} / \mathrm{dl}$. Among the 40 patients
Table VI. Comparisons of single or combined detection results.

\begin{tabular}{llcr}
\hline Index & $\begin{array}{c}\text { Detection } \\
\text { result }\end{array}$ & $\begin{array}{c}\text { Bacterium } \\
\text { group } \\
(\mathrm{n}=70)\end{array}$ & $\begin{array}{r}\text { Virus } \\
\text { group } \\
(\mathrm{n}=40)\end{array}$ \\
\hline PCT & Positive & 56 & 6 \\
Ns-CRP & Pogative & 14 & 34 \\
S-100 & Negative & 60 & 8 \\
& Positive & 56 & 32 \\
PCT + hs-CRP & Negative & 14 & 6 \\
PCT + s-100 & Positive & 61 & 34 \\
Hs-CRP + s-100 & Negative & 9 & 6 \\
& Positive & 61 & 34 \\
PCT + hs-CRP + s-100 & Negative & 9 & 35 \\
& Positive & 60 & 4 \\
& Negative & 10 & 36 \\
& Positive & 69 & 4 \\
& Negative & 1 & 36 \\
\hline
\end{tabular}

in the virus group, there was no obvious improvement in 5 cases, intracranial infection complicated with cerebrospinal fluid 
Table VII. Comparisons of sensitivity, specificity and accuracy of single or combined detection.

\begin{tabular}{lccc}
\hline Index & $\begin{array}{c}\text { Sensitivity } \\
(\%)\end{array}$ & $\begin{array}{c}\text { Specificity } \\
(\%)\end{array}$ & $\begin{array}{c}\text { Accuracy } \\
(\%)\end{array}$ \\
\hline PCT & 80 & 85 & 83 \\
Hs-CRP & 86 & 80 & 83 \\
S-100 & 80 & 85 & 83 \\
PCT + hs-CRP & 87 & 85 & 86 \\
PCT + s-100 & 87 & 88 & 88 \\
PCT + hs-CRP & 86 & 90 & 88 \\
PCT + hs-CRP + s-100 & 99 & 90 & 95 \\
p-value & $<0.05$ & $>0.05$ & $<0.05$ \\
\hline
\end{tabular}

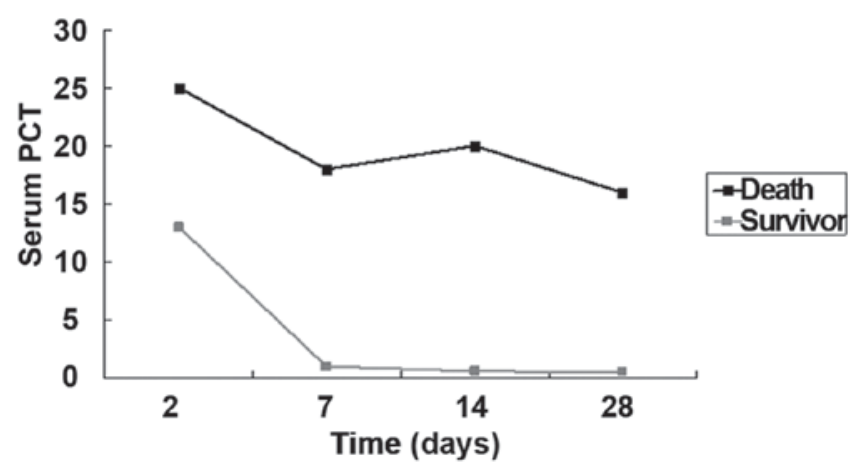

Figure 1. Comparisons of serum PCT between deaths and survivors.

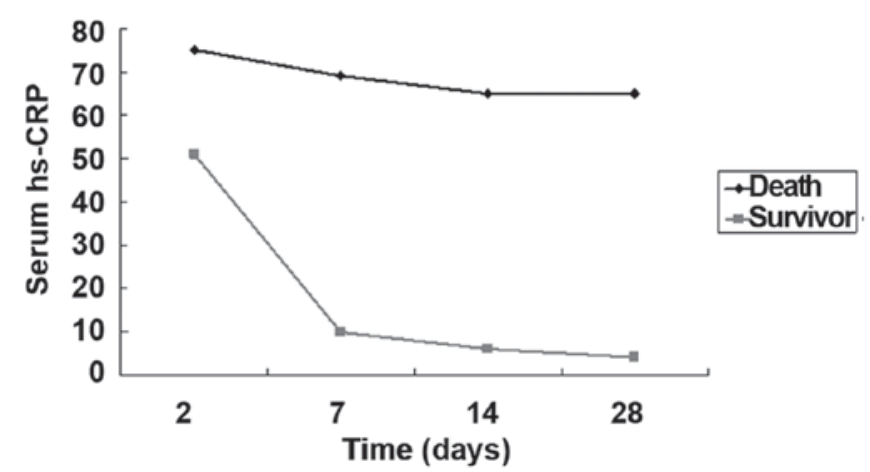

Figure 2. Comparisons of serum hs-CRP between deaths and survivors.

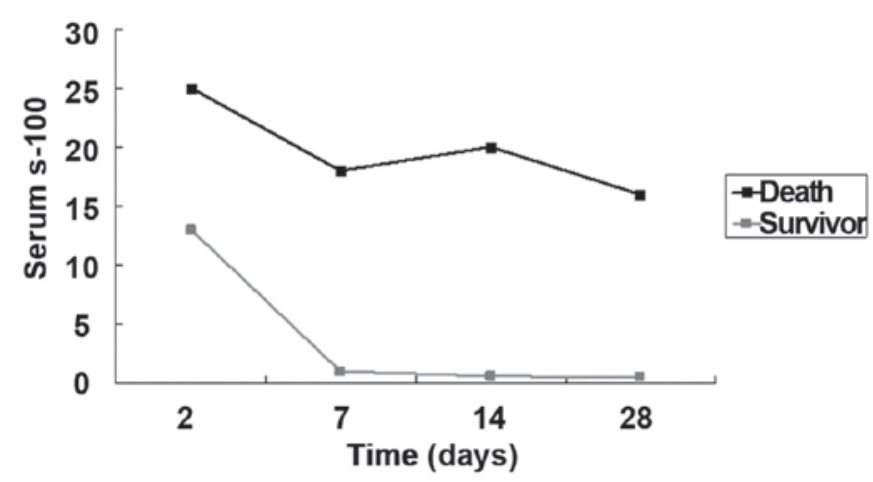

Figure 3. Comparisons of serum s-100 between deaths and survivors. rhinorrhea in 1 case, and intracranial infection complicated with otitis media in 2 cases. After anti-infection and symptomatic treatment, the serum PCT, hs-CRP and s-100 protein levels in 32 patients were gradually decreased (Figs. 1-3).

\section{Discussion}

Human thyroid cells secrete the PCT, forming active ingredients through the hydrolysis of hydrolytic enzymes; when the body is not infected, the serum PCT level cannot be detected generally, or its concentration is very low. When the system infection occurs, especially the bacterial infection, the serum PCT level is significantly increased, and there are differences in different pathogen infections (5), so it can be used to monitor the differential diagnosis of different pathogens in central nervous system infection, severity of disease, dynamic changes in disease and prognosis to a certain extent (6). In some common clinical infections, according to the clinical manifestations of patients and laboratory results, the infection site can be preliminarily understood (7). However, specific pathogenic examination increases the difficulty of diagnosis, because most pathogenic examinations have a low sensitivity, higher cost and lower positive rate (8). In clinical practice, the empirical antiinfection and other symptomatic treatment can be provided, but it can lead to sepsis or multiple organ dysfunction syndrome, and increase the mortality rate due to incorrect medication and rapid development of disease (9). CRP is a kind of reactive protein that can reflect acute infection in the human body, which was considered to be an objective index to determine the bacteriological infection at the earliest stage (10). However, with the continuous improvement of medical technology, the relevant data have shown that the value of CRP is affected by many factors, including special infections, malignancies and other diseases that can lead to elevated CRP to different degrees (11). Therefore, CRP can be used as an auxiliary index for central nervous system infection. PCT can be detected in serum in the early stage of infection, so it can be used as an important basis for the early diagnosis (12).

S-100 protein widely exists in the cytosol of glial cells in the central nervous system. When the central nervous system is damaged, the s-100 protein concentration is also changed (13). Thus, the s-100 protein concentration in cerebrospinal fluid can be used as a reference index for the central nervous system infection (14). In the central nervous system, s-100 protein widely exists in glial cells, astrocytes, macroglial cells and microglial cells. When the central nervous system infection occurs in the body, neurons, glial cells and blood-brain barrier is damaged $(15,16)$. Thus, the s-100 protein enters the interstitial cells, and then enters the blood from the damaged blood-brain barrier, eventually leading to the increased serum s-100 protein level (17). Studies have shown that the level of serum s-100 protein in bacterial infection is significantly higher than that in viral infection and recovery phase in healthy individuals $(14,18)$.

In this study, it was found that the serum PCT, hs-CRP and s-100 protein levels in central nervous system infection in bacterium group were significantly higher than those in the virus and control groups, and there were no statistically significant differences compared with those in cerebrospinal fluid. The serum PCT level can be used in the diagnosis of 
central system infection, differential diagnosis of bacterial and viral infections, determination of the dynamic changes in disease, and guidance of clinical medication. In bacterium group, the PCT, hs-CRP and s-100 levels in deaths were significantly higher than those in survivors, which, to some extent, suggested that the lower the PCT, hs-CRP and s-100 protein levels in the central nervous system infection are, the higher the survival rate will be. The serum PCT, hs-CRP and s-100 protein have higher sensitivity and accuracy for the bacterial infection, and they were not significantly increased in virus group. The clinical detection of serum PCT, hs-CRP and s-100 protein levels can guide the adjustment of therapeutic regimen, assess the severity of disease and evaluate the prognosis. The sensitivity and accuracy of the combined detection were significantly higher than those of single or two-item detection. However, when infection and multiple organ dysfunction syndrome (MODS) occur in the body due to other reasons, the PCT and hs-CRP levels will also be significantly increased, so the central nervous system bacterial infection cannot be determined or the viral infection cannot be completely eliminated only through the single detection of serum PCT, hs-CRP, s-100; instead, the combined detection or comprehensive judgment combined with other means should be used to improve the accuracy of diagnosis (19).

\section{Acknowledgements}

Not applicable.

\section{Funding}

This research did not receive any specific grant from funding agencies in the public, commercial, or not-for-profit sectors.

\section{Availability of data and materials}

The datasets used and/or analyzed during the present study are available from the corresponding author on reasonable request.

\section{Authors' contributions}

JW and XW contributed to the conception of the study. YT contributed significantly to the data analysis and study preparation. XL and XZ performed the data analyses and wrote the study. MZ helped perform the analysis with constructive discussions. All authors have read and approved the final study.

\section{Ethics approval and consent to participate}

The study was approved by the Ethics Committee of the People's Hospital of Rizhao (Rizhao, China). All the subjects enrolled signed the written informed consent.

\section{Patient consent for publication}

Not applicable.

\section{Competing interests}

The authors declare that they have no competing interests.

\section{References}

1. Assicot M, Gendrel D, Carsin H, Raymond J, Guilbaud J and Bohuon C: High serum procalcitonin concentrations in patients with sepsis and infection. Lancet 341: 515-518, 1993.

2. Nylen ES, Whang KT, Snider RH Jr, Steinwald PM, White JC and Becker KL: Mortality is increased by procalcitonin and decreased by an antiserum reactive to procalcitonin in experimental sepsis. Crit Care Med 26: 1001-1006, 1998.

3. Whang KT,Vath SD,Becker KL, Snider RH, Nylen ES, Muller B, Li Q, Tamarkin L and White JC: Procalcitqnin and proinflammatory cytokine interaction in sepsis. Shock 14: 73-78, 2000.

4. Barati M, Alinejad F, Bahar MA, Tabrisi MS, Shamshiri AR, Bodouhi NO and Karimi H: Comparison of WBC, ESR, CRP and PCT serum levels in septic and non-septic burn cases. Burns 34: 770-774, 2008.

5. Alkholi UM, Abd Al-Monem N, Abd El-Azim AA and Sultan MH: Serum procalcitonin in viral and bacterial meningitis. J Glob Infect Dis 3: 14-18, 2011.

6. Viallon A, Guyomarc'h P, Guyomarc'h S, Tardy B, Robert F, Marjollet O, Caricajo A, Lambert C, Zéni F and Bertrand JC: Decrease in serum procalcitonin levels over time during treatment of acute bacterial meningitis. Crit Care 9: R344-R350, 2005.

7. Jereb M, Muzlovic I, Hojker S and Strle F: Predictive value of serum and cerebrospinal fluid procalcitonin levels for the diagnosis of bacterial meningitis. Infection 29: 209-212, 2001.

8. Lorrot M, Moulin F, Coste J, Ravilly S, Guérin S, Lebon P, Lacombe C, Raymond J, Bohuon C and Gendrel D: Procalcitonin in pediatric emergencies: Comparison with $\mathrm{C}$-reactive protein, interleukin- 6 and interferon alpha in the differentiation between bacterial and viral infections. Presse Med 29: 128-134, 2000 (In French)

9. Knudsen TB, Larsen K, Kristiansen TB, Møller HJ, Tvede M, Eugen-Olsen J and Kronborg G: Diagnostic value of soluble CD163 serum levels in patients suspected of meningitis: Comparison with CRP and procalcitonin. Scand J Infect Dis 39: 542-553, 2007.

10. Taskin E, Turgut M, Kilic M, Akbulut H and Aygun AD: Serum procalcitonin and cerebrospinal fluid cytokines level in children with meningitis. Mediators Inflamm 13: 269-273, 2004.

11. Kang YA, Kwon SY, Yoon HI, Lee JH and Lee CT: Role of C-reactive protein and procalcitonin in differentiation of tuberculosis from bacterial community acquired pneumonia. Korean $\mathbf{J}$ Intern Med 24: 337-342, 2009.

12. Jiang J, Shi HZ, Liang QL, Qin SM and Qin XJ: Diagnostic value of interferon-gamma in tuberculous pleurisy: A metaanalysis. Chest 131: 1133-1141, 2007.

13. Carrol ED, Newland P, Thomson AP and Hart CA: Prognostic value of procalcitonin in children with meningococcal sepsis. Crit Care Med 33: 224-225, 2005.

14. Stich O, Andres TA, Gross CM, Gerber SI, Rauer S and Langosch JM: An observational study of inflammation in the central nervous system in patients with bipolar disorder. Bipolar Disord 17: 291-302, 2015.

15. Petros S, Leonhardt U and Engelmann L: Serum procalcitonin and proinflammatory cytokines in a patient with acute severe leptospirosis. Scand J Infect Dis 32: 104-105, 2000.

16. Mills GD, Lala HM, Oehley MR, Craig AB, Barratt K, Hood D, Thornley CN, Nesdale A, Manikkam NE and Reeve P: Elevated procalcitonin as a diagnostic marker in meningococcal disease. Eur J Clin Microbiol Infect Dis 25: 501-509, 2006.

17. Christ-Crain M, Jaccard-Stolz D, Bingisser R, Gencay MM, Huber PR, Tamm M and Müller B: Effect of procalcitonin-guided treatment on antibiotic use and outcome in lower respiratory tract infections: Cluster-randomised, single-blinded intervention trial. Lancet 363: 600-607, 2004

18. Viallon A,Pouze V, Zéni F, Tardy B, Guyomarc'h S, Lambert C, Page Y and Bertrand JC: Rapid diagnosis of the type of meningitis (bacterial or viral) by the assay of serum procalcitionin. Presse Med 29: 584-588. 2000 (In French).

19. Dubos F, Korczowski B, Aygun DA, Martinot A, Prat C, GalettoLacour A, Casado-Flores J, Taskin E, Leclerc F, Rodrigo C, et al: Distinguishing between bacterial and aseptic meningitis in children: European comparison of two clinical decision rules. Arch Dis Child 95: 963-967, 2010. 